\title{
The role of reminding in long-term memory for temporal order
}

\author{
WiLliam J. Friedman \\ Oberlin College, Oberlin, Ohio
}

\begin{abstract}
Order codes are one of the three main types of information that have been hypothesized to underlie memory for the times of life events. Published evidence for the theory, however, has come exclusively from research in which brief retention intervals have been used. In the first of two studies, 101 adults judged the order of pairs of movies released 5-14 years ago, half of which shared a common major actor. There was no evidence that related films could be ordered more accurately than unrelated ones. In the second study, 88 students were presented with in-class announcements that were either related or unrelated to an earlier announcement. Three weeks later, they judged the order of the pairs of announcements. There was no difference between the accuracy for the related and the unrelated pairs. The findings do not support the proposal that the automatic creation of order information at the time of encoding contributes to autobiographical memory.
\end{abstract}

An important aspect of the experience of remembering past events is the feeling that the events belong to specific times in our past. When asked, we can usually provide at least an approximate answer to the question of when an event took place. A considerable body of theory and research has been devoted to explaining the processes that underlie humans' chronological sense of their past (for summaries, see Friedman, 1993, 1996, 2001; Thompson, Skowronski, Larsen, \& Betz, 1996). When this body of theory and evidence is considered, it is useful to distinguish between three kinds of temporal information: locations, distances, and order (Friedman, 1993). Locations refer to particular times in a temporal pattern, whether the pattern is based in nature (e.g., spring), social convention (Wednesday), or the outline of one's own life (college years). Distances are amounts of time that have elapsed between some event and the present. Order refers to before-after relations between events. Although adults are adept at converting one type of information into another, the elementary information that allows us to reckon past times is likely to take one of these forms.

In laboratory studies and research on memory for the times of life events, a particular type of location-based theory, reconstructive theory (e.g., Friedman \& Wilkins, 1985; Hintzman, Block, \& Summers, 1973), has received the strongest support (Brewer, 1996; Friedman, 1993; Thompson et al., 1996). In these models, contextual information associated with an event is combined with general knowledge of time patterns to infer when the event must have taken place. For example, remembering the approximate age of one's child at the time of some target event often proves useful in recalling the time of the event. Despite the strong support for reconstructive theories, it is now clear that distance processes also play some role in human memory for time (Friedman, 1996, 2001). Impressions of the ages of memories are especially likely to be used when the possibility of reconstruction is precluded, as when contextual cues are undifferentiated (Friedman \& Huttenlocher, 1997), the events to be compared are at very different distances in the past (Bastin, Van der Linden, Michel, \& Friedman, 2004; Curran \& Friedman, 2003), or the participants are young children (Friedman, 1991).

The third type of temporal information, relations of order, has been the subject of a prominent theory of memory for time (Hintzman, Summers, \& Block, 1975; Tulving, 1983; Tzeng \& Cotton, 1980; Winograd \& Soloway, 1985), called the order code theory here. The central idea is that temporal information is created at the time of encoding when one event causes the retrieval of an earlier event. The retrieval is believed to automatically create a temporal pointer between the later and the earlier event, and the pointer becomes part of the trace of the later event. This temporal information can be accessed at the time of recall and used to judge the order in which the earlier and the later events occurred. The initial reminding process is far more likely to occur when there is a semantic relation between a later and an earlier event. This leads to the prediction that participants in laboratory studies will be more accurate when judging the order of related items from a list (e.g., two words from the same semantic category or two words that are strongly associated) than when making similar judgments for pairs of unrelated items. Laboratory studies have provided strong support for this prediction (Nairne \& Neumann, 1993; Tzeng \& Cotton, 1980; Winograd \& Soloway, 1985).

Despite the clear evidence from these laboratory studies, very little is known about the role of the hypothesized 
reminding process in autobiographical memory. In a number of discussions of the order code theory (e.g., Friedman, 1990, 2004; Winograd \& Soloway, 1985), the authors have stated or implied that the reminding process contributes to long-term memory of life or news events. For example, Winograd and Soloway (1985) proposed that order codes could permit one to remember, many years later, the order in which the rescue of Israeli hostages at Entebbe and the attempted rescue of American hostages in Iran took place. It could also help one to remember the order in which the Three Mile Island and Chernobyl nuclear accidents occurred (Friedman, 1990). It is unclear, however, whether automatic reminding is sufficient to explain these abilities. In memory for life and public news events, it is more likely than it is in the laboratory studies that active processing of the relation between the two events will follow that reminding. Such elaboration must have been quite limited in Nairne and Neumann's (1993), Tzeng and Cotton's (1980), and Winograd and Soloway's (1985) studies, given the many stimuli, the rapid pace of presentation, and the relatively impoverished nature of the relations between the items. The fact that the participants were nonetheless superior in the ordering of related, as opposed to unrelated, pairs suggests that an automatic reminding process creates order information that can be retained over a period of many minutes. But does automatic reminding create information that can be used in long-term memory, or is more active processing at the time of encoding necessary?

In addition to this distinction between automatic reminding and the more active processing initiated by automatic reminding, both must be distinguished from other ways of knowing the order of two events. In studies of autobiographical memory, relations of order can often be inferred at the time of retrieval, without any relations having been established at the time of encoding. An example is the ability to compare the times of events that come from different "lifetime periods" (Conway, 1996), such as the years one was in college and the years of one's first job. Of course, the order of many other pairs of events can also be inferred on the basis of temporal-causal connections between them, relations that would be known to most people even if they had not experienced the events. To study encoding-related mechanisms in long-term memory, it is important to examine relatedness effects under conditions in which reconstruction of the order is difficult.

The emphasis in the present research was on the processes underlying order information in autobiographical memory. Hence, retention intervals were chosen that were longer than those used in the laboratory studies. The first study involved retention intervals of many years. As is usual in research with such long time scales, this required sacrificing experimental control of the events that took place at the time of encoding and relying, instead, on stimulus selection. The design of the study called for pairs of events in very long term memory for which meaningful temporal relations were quite limited, reminding of the first event was likely to have occurred with some frequency when the second event occurred, and active processing of the temporal relation at this time was probably infrequent. The task was judging the order of pairs of movies, some of which had the same main actor and others of which were unrelated in this way. The assumption was not that seeing an actor in a movie always reminds the viewer of seeing him or her in a previous movie but that this occurs some modest percentage of the time. The experience of watching a movie was presumed to be sufficiently engrossing that little elaboration of the meaning of the temporal relation would take place. Films that were the first major film for an actor and films that were sequels were excluded, because these could permit judgments based on inference.

To increase the participants' reliance on order information, temporal parameters were chosen that should make distance-based processes difficult to use and reduce the frequency with which the two movies could be linked to different lifetime periods. All the movies were at least 5 years old, and separations were selected so that the ratio of elapsed time of the more recent to the less recent film was greater than .70. Previous studies of distance-based processes have revealed functions relating the subjective to the objective age of events such that pairs with ratios this large would differ little in their subjective recency (Friedman, 1996, 2001). Relatively narrow separations, 3 years or less in this study, also increase the likelihood that a particular Movie 1 will have been retrieved when Movie 2 was seen.

\section{STUDY 1}

\section{Method}

\section{Participants}

All employees of Oberlin College were sent a two-page mailing at the beginning of June 2004. Of the more than 1,000 recipients, 140 replied. The responses were anonymous, so the sample is an unknown mix of faculty and other employees.

\section{Materials and Procedure}

The mailing contained the following instructions:

On the following page are pairs of movie titles. Please go through the list one pair at a time. First cross out movies in the pair that you have not seen. Then, if you have seen them both, please judge as best you can which of the movies you saw a longer time ago. Write a " 1 " next to the movie that you saw earlier and a " 2 " next to the movie you saw later. The comparisons are designed to be very difficult. It is expected that you will need to guess for most pairs. Even if you are unsure about all of the pairs you have seen, your responses will still be valuable. Please include only films that you think you saw in a movie theater. If you saw a movie on videotape or DVD, cross it out. Also cross out movies you have seen more than once. Please respond based on your own memory, without checking with anyone else or using any other source of information.

The following page contained the titles of the movie pairs listed in Table 1 in that order. This was a random ordering of the 10 related and 10 unrelated pairs, with a randomly determined half presenting the older movie in the pair first. At the end of the list were the following instructions. "Optional: On the back, briefly explain how you think you arrived at your order judgments (for the pairs where you had seen both movies). If this was different on different pairs, please mention several methods you used."

The stimuli were selected according to a number of criteria, in addition to those mentioned in the introduction. We examined a pool of movies that were released between 1990 and 1999 that had been among the National Board of Review's top 10 films for the year and/or 
Table 1

Stimulus Pairs in Study 1

\begin{tabular}{ll}
\hline \multicolumn{1}{c}{\begin{tabular}{c}
\multicolumn{1}{c}{ Film Pairs } \\
(Dates in Parentheses)
\end{tabular}} & $\begin{array}{c}\text { Common Actor } \\
\text { (for Related Pairs) }\end{array}$ \\
\hline $\begin{array}{l}\text { Clear and Present Danger (1994) - Mrs. Doubtfire (1993) } \\
\text { Crimson Tide (1995) - Malcolm X (1992) }\end{array}$ & $\begin{array}{l}\text { Denzel Washington } \\
\text { The Fugitive (1993) - Clear and Present Danger (1994) } \\
\text { Malcolm X (1992) - Much Ado About Nothing (1993) }\end{array}$ \\
$\begin{array}{l}\text { Schindler's List (1993) - Four Weddings and a Funeral (1994) } \\
\text { Awakenings (1990) - The Fugitive (1993) }\end{array}$ & \\
Runaway Bride (1999) - Shakespeare in Love (1998) & \\
Groundhog Day (1993) - Four Weddings and a Funeral (1994) & \\
Crimson Tide (1995) - Peter's Friends (1992) & Andie MacDowell \\
The Talented Mr. Ripley (1999) - My Best Friend's Wedding (1997) & \\
Mrs. Doubtfire (1993) - Awakenings (1990) & Robin Williams \\
American Beauty (1999) - Midnight in the Garden of Good and Evil (1997) & Kevin Spacey \\
Shakespeare in Love (1998) - The Talented Mr. Ripley (1999) & Gwyneth Paltrow \\
The Rock (1996) - Con Air (1997) & Nicolas Cage \\
The English Patient (1996) - Schindler's List (1993) & Ralph Fiennes \\
Midnight in the Garden of Good and Evil (1997) - The Rock (1996) & \\
American Beauty (1999) - Con Air (1997) & \\
Peter's Friends (1992) - Much Ado About Nothing (1993) & \\
My Best Friend's Wedding (1997) - Runaway Bride (1999) & Kenneth Branagh \\
Groundhog Day (1993) - The English Patient (1996) & Julia Roberts \\
\hline
\end{tabular}

were among the top-grossing films for their year. Of these, we chose movies that had a well-known actor or actress in a major role in more than one film in the set and ones that seemed likely to have been seen by our demographic and age groups. Each of the final 20 movies was paired with 1 other film featuring a common major actor or actress (related pairs) and another film without a common actor or actress in a major part (unrelated pairs). Each related pair was matched with an unrelated pair in the years in which the 2 movies were released.

\section{Results}

\section{Accuracy}

Of the 140 respondents, 39 reported no pairs for which they had seen both movies. The remaining participants reported a total of 569 pairs, 307 related and 262 unrelated. The difference between the numbers of related and unrelated films was significant by a two-tailed Wilcoxon test $(p<.001)$, and it was consistent with people preferring, and actors tending to appear in, particular types of films.

Of the related films, 193 order judgments were correct, and 114 were incorrect (mean proportion correct $=.63$ ). For the unrelated films, the corresponding numbers were 178 and 84 (.68). Temporal accuracy was significantly greater than chance expectations for both the related and the unrelated sets. Of those participants who judged at least one related pair, the mean proportion correct exceeded the null expectation of $.50[t(95)=3.27$, one-tailed $p=$ $.001]$. The same was true for the participants who judged at least one unrelated pair $[t(88)=5.11, p<.001]$.

If automatic reminding occurred, at the time of encoding, more often in the related than in the unrelated pairs and if this created order codes that would persist for many years, we would expect higher rates of accuracy for the related pairs. This was not the case. The large number of data points would have made it possible to detect even a weak advantage for related films in the following analysis. The 84 participants who reported having seen at least one related and one unrelated pair had mean proportions correct similar to those for the tallies of numbers of pairs judged: .61 $(S D=.35)$ for related pairs and $.69(.33)$ for unrelated pairs. A two-tailed Wilcoxon test revealed that the difference approached significance $(p=.060)$, but in the direction opposite to that predicted by order code theories.

There was evidence of a weak bias to select the movie listed on the left as having occurred earlier. The participants were more accurate when the earlier movie was on the left of the page $(M=1.43, S D=1.84)$ than when the earlier movie was on the right $(M=1.22, S D=1.61)[t(139)=$ $2.11, p=.036]$. Because 6 of the 10 related pairs had the earlier movie presented on the left, this might have inflated, but not reduced, the accuracy of the related pairs.

In addition to their status as related or unrelated, the pairs differed somewhat in their temporal characteristics. Correlations of the mean accuracy of each of the 20 pairs with the age of the more recent movie in years (lag), the difference in the ages (separation), and the ratio of the shorter to the longer distance (ratio) were examined. Given the restricted ranges for these values and the small number of pairs, it is not surprising that none of these variables was significantly related to accuracy. However, there was a modest lag effect $(r=.36, p=.121)$, suggesting some loss of temporal information between 5 and 10 years. There was also a weak ratio effect $(r=.39, p=.085)$. Ratio effects can be a sign that distance-based processes have been used. The weak ratio effect indicates that the inclusion only of ratios larger than .70 may have limited the participants' ability to benefit from this approach. The correlation between accuracy and separation was very weak, both for the set as a whole and for the related pairs alone.

\section{Method Reports}

Sixty-two participants responded to the optional question about the methods used. Twenty of these were explanations of why they had made few or no judgments (e.g., only viewing films on video or DVD). Of the explanations 
of the methods used to arrive at judgments, 25 were clearly consistent with reconstruction. The most common such reports involved remembering where the participants or persons with whom the movie had been seen had lived at the time of a movie or other ways of relating movies to periods in their lives. Five participants reported relying on impressions of distances (e.g., which movie was perceived to be older), and another 2 participants mentioned this approach along with reconstruction. Ten other participants produced responses that could not be classified (e.g., all guesses or just by memory). For the only one of these categories for which substantial numbers of accuracy scores were available, reconstruction, accuracy means were close to those for the whole sample: .64 for related pairs and .58 for unrelated pairs. Three participants reported having specialized knowledge of film or remembering actors' biographies. Ten out of 15 of their judgments were correct for related films.

\section{Discussion}

This study was conducted to help answer the question of whether order codes, automatically established at the time of encoding, contribute to long-term autobiographical memory. Such a process should lead to greater accuracy in judging the order of related pairs of events than in judging that of unrelated pairs. The results showed a borderline-significant difference in the opposite direction to that predicted by order code theories.

A possible criticism of the theoretical relevance of these findings is that although order codes may be automatically formed and persist in very long term memory, they are very rarely formed between the related stimuli used in this study-movies with a common major actor. Perhaps participants seldom retrieve memories of an actor's performance in an earlier film when he or she is seen in a later film. This is not a matter that can be resolved in this study. One can imagine reasons why such retrieval is likely (e.g., a stimulus match of the actor's appearance, their name being mentioned before or after each movie, or separations of only a few years) and factors that might stand in the way of retrieval (e.g., being engrossed in the film, not being familiar with the actor, or being reminded of an earlier film with the actor but not the one that was the comparison item in this study). Method reports cannot help resolve this issue, because an automatic process, or any process occurring more than 5 years ago, would not be remembered and participants who access an existing order code while completing the survey might be unaware of the fact that they are doing so. Before this explanation of the findings can be accepted or ruled out, evidence is needed from other situations where there is stronger reason to believe that reminding takes place but that inference of the order at the time of recall would be difficult. The second study was designed to provide such evidence.

\section{STUDY 2}

In this study, some of the design features of the first study were preserved, including using pairs of events whose order would be difficult to reconstruct and selecting ratios of distances in the past that should reduce the likelihood that the participants could arrive at accurate judgments on the basis of distance-based processes. The main difference was that in Study 2, the conditions that were selected made it very likely that the first event in the related pairs would be retrieved when the second one occurred, and the frequency of such reminding was checked in an independent sample. Another difference was that the retention interval was much shorter than that in Study 1, about 3 weeks. Although this retention interval is much shorter than the scales usually sampled in studies of autobiographical memory, it is still much longer than those in the laboratory studies, and the results may, therefore, be more relevant than the laboratory studies to an evaluation of the role of order codes in autobiographical memory.

\section{Method}

\section{Participants}

The participants in the main part of the study were the 88 students from an introductory psychology course at Oberlin College who were present on the test day. In the class as a whole $(N=98), 60 \%$ of the students were female. In the comparison condition, the participants were 18 students from a course in developmental psychology who were present on the test day. Of the 21 students in this class, $71 \%$ were female.

\section{Materials and Procedure}

Main study. The stimulus events occurred on two consecutive class meetings, February 22 and 24, 2005. On the 1st of the 2 days, the instructor read the following announcement near the start of class. "A student with an earlier class in this room has lost a folder of drawings. Please let me know if you found it. The folder contained architectural drawings, mainly of buildings in London and Paris, along with human figure drawings."

Two days later, the instructor read the following announcement, which was intended to remind students of the one read on the 1 st day. "A student has asked if anyone has found a book she might have left in this classroom. It is a rare book on Chinese herbal medicine. The book has a green cover, with calligraphy and pictures of plants." This was followed by a filler announcement about meeting course requirements and then another staged announcement, which was designed to be unrelated to the one presented on the 1st day:

There was a story about an Oberlin grad. in the news that might be of interest to psychology students. I have the web address if you'd like to see it. (Student's name), a graduate student at Cornell, needs to be able to read colored maps of the upper atmosphere, but (student's name) is blind. With the help of others, he has developed a prototype program that allows him to track a pen across a graphics pad, and the computer generates one of 88 piano notes corresponding to colors. (The student's) ability to imagine a color map of the data may depend on the fact that he lost his sight at age seven and still has some color memory.

Testing took place in class on March 15. This was 21 and 19 days after the days of the announcements, a ratio of temporal distances of the more recent to the less recent event of .90 . The students filled out a two-page survey. The first page began with the following instructions. "Listed below are three events. Please circle the place on the corresponding 7-point scales that indicates how well you remember each of them." Descriptions of the three events appeared in one of the six possible orders, each accompanied by a 7-point rating scale. The low end of the scale was labeled "Don't remember/wasn't there/didn't happen," and the high end was labeled "Remember very clearly." Responses were converted to numbers from 0 to 6 .

The announcement from the 1st day, called the drawing event here, was summarized as follows: "An announcement about a lost folder 
Table 2

Numbers of Participants Making Particular Order Judgments in Study 2

\begin{tabular}{ccccc}
\hline & \multicolumn{3}{c}{ Order Judgment } & \\
\cline { 2 - 3 } & \multicolumn{2}{c}{$\begin{array}{c}\text { Event Judged } \\
\text { Earlier }\end{array}$} & Same & $\begin{array}{c}\text { One or Both } \\
\text { Pair }\end{array}$ \\
\cline { 2 - 3 } & Correct & Incorrect & Day & Not Remembered \\
\hline Different day & & & & \\
$\quad$ Related & 25 & 16 & 3 & 44 \\
$\quad$ Unrelated & 23 & 15 & 5 & 45 \\
Same day & 24 & 14 & 5 & 43 \\
$\quad$ Unrelated* & 24 & & & \\
\hline
\end{tabular}

*The correct answer was "same day." Correct and incorrect in this row refer to the order of mention within that day.

of drawings of buildings, mainly in London and Paris, and humanfigure drawings." The announcement from the 2nd day, which was related to the 1st-day announcement, will be called the book event. The description was the following: "An announcement about a lost rare book on Chinese herbal medicine, with a green cover with calligraphy and plants." The unrelated announcement from the 2nd day, the graduate event, was described as follows: "A news story about a blind Oberlin grad. who helped develop a computer program that converts colors in maps to piano notes."

On the second page, the students were asked to judge the order of each of the pairs of events. The instructions were as follows. "Below are pairs of events. Please go through them and cross out events that you do not remember at all. Then, if you remember both in a pair, please judge as best you can the order in which the two occurred. Write a ' 1 ' next to the event that occurred on an earlier day and a ' 2 ' next to the event that occurred on a later day. If both happened the same day, write "same." The same-day option was not directly relevant to the order code hypothesis, but it allowed a test of whether the students were able to remember that the book and the graduate events occurred close in time. Two theories of memory for time, temporal organization and time-tagging theories (see Friedman, 1993), seem to imply that we should have access to the information that temporally proximal events occurred at about the same time, although the very limited available evidence runs against this prediction (Friedman \& Huttenlocher, 1997; Wagenaar, 1986).

Below the instructions were the three pairs of events, each pair separated by a dotted line. The event descriptions were the same as those on page 1. Order of the pairs and left-right assignment were counterbalanced. For each pair, which events were crossed out was coded, and the order judgment for those pairs where neither event was crossed out was recorded.

Comparison condition. The students in the developmental psychology class were read the drawing announcement on a Wednesday, and they were read the book announcement 2 days later, on Friday. Immediately after the book announcement on Friday, they were instructed as follows:

I'd like to ask your help with a study. Please take out the sheet of paper I distributed. When you heard me read it, did this announcement about the lost book remind you of something else that happened previously? If so, write a brief description above the line. (After allowing time to do so:) Did it remind you of the announcement about the lost folder of drawings? Write "yes" or "no" below the line. If you were not in class on Wednesday, please write that at the bottom.

\section{Results}

\section{Comparison Condition}

Of the 18 students present on the second, test day, 13 $(72 \%)$ reported correct information (e.g., sketchbook, ar- chitectural drawings) or gist-like information (e.g., photos) about the drawing announcement, and 1 other recalled only that something had been lost. When asked whether the book announcement had reminded them of the drawing announcement, 14 participants (78\%) answered "yes."

\section{Main Study}

Memory ratings. For the drawing, book, and graduate events, 31,29 , and 20 of the 88 participants, respectively, gave ratings of zero. Assuming the same rate of attendance on the announcement days as on the test day (90\%), we can estimate that between about .13 and .25 of the students had forgotten particular events about 3 weeks after they had occurred.

The mean memory ratings, including zeros, for the drawing, book, and graduate announcements were 2.59 $(S D=2.35), 2.78$ (2.46), and 3.25 (2.37). Variation between these means was only marginally significant $[F(2,87)=3.02, p=.051]$.

Order judgments. The results for the judgments of the order of the pairs of events are presented in Table 2. The first row displays the results for related announcements separated by 2 days, the second row for unrelated announcements separated by 2 days, and the third row for unrelated announcements presented minutes apart. The data in the rightmost column show that about half of the participants did not remember one or both of the events in each pair (as indicated by the crossing out of events). The first two rows can be used to test the prediction of order code theories that participants will be more accurate in recalling the order of related pairs than in recalling that of unrelated pairs. There is no support for this prediction. If we disregard the same judgments, which are neutral with respect to the theory (order codes should not contain information about the magnitude of the interval separating the two events), the proportions correct are the same, rounding to .61 for both the related and the unrelated pairs. In neither case was accuracy reliably greater than chance expectations [binomial $p$ s (two tailed) $=.21$ and .16 for the related and the unrelated pairs, respectively].

The data in the last row bear on the questions about memory for the temporal contiguity of unrelated events. Such an ability might be expected if information about locations in linear time were uniformly assigned to events when they occur or if memory were organized chronologically (see the discussion of time-tagging and chronological organization theories in Friedman, 1993). This is because, under these theories, it should be possible to detect the similarity of the two time tags of events that occurred at about the same time or their similar locations in the memory store. There was no support for this expectation. Same judgments were no more common for announcements presented minutes apart than for announcements presented 2 days apart.

\section{Discussion}

The results of the comparison condition indicate that nearly $80 \%$ of the students in the main condition were likely to have been reminded of the announcement of the 
1st day when the related announcement was made on the 2nd day. But when tested about 3 weeks later, even those students who recalled both events showed no greater facility in judging the order of the related pair than in judging that of the unrelated pair. These findings provide no support for the retention of order information over the several-week interval.

The results also showed that the participants were unable to remember the temporal contiguity of the two events presented minutes apart. These findings replicate those of two previous studies of memory for the temporal contiguity of unrelated events. Wagenaar (1986) tested his memory for events that occurred over a 5-year period. On the 157 days on which his records showed that there were two events from the same day, he used one event as the cue and the other as the target. Wagenaar's ability to remember same-day contiguity was very poor, except for a small number of days for which the pairs were "clearly related by the location at which the events took place" (p. 246). In the other study, Friedman and Huttenlocher (1997) tested memory for the times of stories from the television news magazine program "60 Minutes," stories that had been presented over the previous 9 months. Among the measures were order judgments for pairs of stories, all unrelated, that had been presented during the same show or on different weeks. Same-week judgments were no more common for stories that had been presented within the same broadcast hour than for those presented on different weeks.

The failure in all three studies to find evidence of memory for the temporal proximity of two same-day events may seem at odds with a common finding in studies of memory for the times of personal and public events: participants' reports that they arrived at their judgments by remembering other events that had happened at about the same time as the target event (e.g., Brown, Shevell, $\&$ Rips, 1986). It may be that such events are linked in memory only when a meaningful relation between the two is encoded through active processing that takes place around the time that they occur.

\section{GENERAL DISCUSSION}

In neither of these two studies was there evidence that the order of related events could be recalled better than the order of unrelated pairs of events. These are null findings, but they appear to be at odds with those from the laboratory studies designed to evaluate order code theories. A possible reconciliation is that order codes often are created automatically but are lost over the longer retention intervals sampled in this study. We know from the laboratory studies (Nairne \& Neumann, 1993; Tzeng \& Cotton, 1980; Winograd \& Soloway, 1985) that order information can be created with little active processing and can be retained over many minutes. Even the theorists who have hypothesized that reminding is important in the creation of temporal information in memory have not believed that order codes will always be remembered. For example, Tulving (1983) proposed that order codes are recorded as part of the trace of an event. But in many instances in which this occurs, we might expect the order codes to be lost or to become difficult to access over long intervals of time. Perhaps the title of a film and experience of seeing it in a theater (Study 1) and the experience of the two class announcements (Study 2) were often preserved in memory, but the order code was not. However, if automatic order codes are seldom accessible on the time scales tested in this study, ranging from weeks to years, they would not seem to be important in explaining the ability to judge the times of autobiographical events.

Perhaps reminding does automatically create order codes, but in the absence of active processing of the temporal relation at the time of encoding, this information is preserved only for a limited (and as yet unknown) amount of time. Under this explanation, reminding provides an opportunity to think about the connection between a current event and earlier, related events. Where two events are of sufficient interest, this might include a search for a causal connection, consistency or inconsistency with knowledge about common temporal sequences (e.g., marriage usually precedes having a child; see the relevant example in Friedman \& Wilkins, 1985, p. 170), or some other relation that is significant for the person. If no notable relation is found, order information is not preserved in memory.

This kind of selectivity may be necessary because reminding must occur with great frequency and can, thus, potentially create a tremendous amount of order information. Reminding is of considerable functional importance, since it allows us to use our memory of past situations to deal with new ones. Reminding must also be responsible for schema formation: Information about new events is connected to prior events that are related, and the new and old information are integrated. But the temporal order information that can be created by reminding is probably of little use in the vast majority of instances in which the process occurs. Indeed, the value of schematizing a frequent type of event lies not in the details of individual instances, such as their order, but in the features shared by many instances - those features most likely to apply to future events (McCrone, 2004).

Even if this selectivity account is correct, we know very little about the conditions that are necessary for the creation of durable order information. For this reason, it is difficult to know how important prestored relations of order are for humans' chronological sense of the past. In the present study, there was no evidence that the relatedness of the movies or the announcements contributed to the participants' accuracy. The fact that accuracy was greater than would be expected by chance in Study 1 can be explained by the other two main types of temporal information in memory - contextual cues that can be used to reconstruct temporal locations and information about temporal distances. Although the temporal parameters were chosen here to reduce the utility of reconstruction and distancebased processes, there is reason to believe that both were used. As in past studies (e.g., Brown et al., 1986; Friedman \& Wilkins, 1985; Linton, 1975), the participants frequently reported using memory for the context of an event (e.g., where he or she had lived at the time) to reconstruct its likely time. In addition, a number of the participants referred to impressions of how long ago they had seen a 
movie, and the correlation between ratio and accuracy may have been a weak signature of distance-based processes. In contrast, there was no support for the hypothesis that motivated this study: that order codes, automatically established at the time of encoding, are a significant source of temporal information in long-term memory.

\section{AUTHOR NOTE}

This material is based on work supported by the National Science Foundation under Grant 0241558. Any opinions, findings, and conclusions or recommendations expressed in this material are those of the author and do not necessarily reflect the views of the National Science Foundation. I am grateful to Leslie Worcester for her help in selecting the stimuli for the first study and Patricia deWinstanley for her suggestions and assistance with the conduct of the second study. Address correspondence to W. J. Friedman, Department of Psychology, Oberlin College, Oberlin, OH 44074 (e-mail: friedman@ oberlin.edu).

Note-This article was accepted by the previous editorial team, when Colin M. MacLeod was Editor.

\section{REFERENCES}

Bastin, C., Van der Linden, M., Michel, A.-P., \& Friedman, W. J. (2004). The effects of aging on location-based and distance-based processes in memory for time. Acta Psychologica, 116, 145-171.

Brewer, W. F. (1996). What is recollective memory? In D. C. Rubin (Ed.), Remembering our past: Studies in autobiographical memory (pp. 19-66). Cambridge: Cambridge University Press.

Brown, N. R., Shevell, S. K., \& Rips, L. J. (1986). Public memories and their personal context. In D. C. Rubin (Ed.), Autobiographical memory (pp. 137-158). Cambridge: Cambridge University Press.

Curran, T., \& Friedman, W. J. (2003). Differentiating location- and distance-based processes in memory for time: An ERP study. Psychonomic Bulletin \& Review, 10, 711-717.

FRIEDMAN, W. J. (1990). About time: Inventing the fourth dimension. Cambridge, MA: MIT Press, Bradford Books.

Friedman, W. J. (1991). The development of children's memory for the time of past events. Child Development, 62, 139-155.

Friedman, W. J. (1993). Memory for the time of past events. Psychological Bulletin, 113, 44-66.

FriedMAN, W. J. (1996). Distance and location processes in memory for the times of past events. In D. L. Medin (Ed.), The psychology of learning and motivation (Vol. 35, pp. 1-41). Orlando, FL: Academic Press.

Friedman, W. J. (2001). Memory processes underlying humans' chronological sense of the past. In C. Hoerl \& T. McCormack (Eds.), Time and memory: Issues in philosophy and psychology (pp. 139-167). Oxford: Oxford University Press.

Friedman, W. J. (2004). Time in autobiographical memory. Social Cognition, 22, 605-621.

Friedman, W. J., \& Huttenlocher, J. (1997). Memory for the times of "60 Minutes" stories and news events. Journal of Experimental Psychology: Learning, Memory, \& Cognition, 23, 560-569.

FRIEDMAN, W. J., \& WILKINS, A. J. (1985). Scale effects in memory for the time of events. Memory \& Cognition, 13, 168-175.

Hintzman, D. L., BLOCK, R. A., \& Summers, J. J. (1973). Contextual associations and memory for serial position. Journal of Experimental Psychology, 97, 220-229.

Hintzman, D. L., Summers, J. J., \& Block, R. A. (1975). Spacing judgments as an index of study-phase retrieval. Journal of Experimental Psychology: Human Learning \& Memory, 1, 31-40.

Linton, M. (1975). Memory for real world events. In D. A. Norman \& D. E. Rumelhart (Eds.), Explorations in cognition (pp. 376-404). San Francisco: Freeman.

McCrone, J. (2004, January 30). Reasons to forget: Scientists count the ways we get it wrong. Times Literary Supplement, pp. 3-4.

NaIRne, J. S., \& Neumann, C. (1993). Enhancing effects of similarity on long-term memory for order. Journal of Experimental Psychology: Learning, Memory, \& Cognition, 19,329-337.

ThOMPSON, C. P., SKOWRONSKI, J. J., LARSEN, S. F., \& Betz, A. (1996). Autobiographical memory: Remembering what and remembering when. Mahwah, NJ: Erlbaum.

Tulving, E. (1983). Elements of episodic memory. Oxford: Oxford University Press, Clarendon Press.

Tzeng, O. J. L., \& CotTon, B. (1980). A study-phase retrieval model of temporal coding. Journal of Experimental Psychology: Human Learning \& Memory, 6, 705-716.

WAgEnAaR, W. A. (1986). My memory: A study of autobiographical memory over six years. Cognitive Psychology, 18, 225-252.

Winograd, E., \& Soloway, R. M. (1985). Reminding as a basis for temporal judgments. Journal of Experimental Psychology: Learning, Memory, \& Cognition, 11, 262-271.

(Manuscript received July 30, 2004; revision accepted for publication October 28, 2005.) 